\title{
Práticas avaliativas no ensino de inglês para alunos com deficiência múltipla: explorando a inteireza do possível
}

\author{
Assessment practices to students with multiple disabilities in \\ English classes: exploring the entirety of possible experiences
}

Rosycléa Dantas

rosycleads@hotmail.com

Universidade Federal da Paraíba

\begin{abstract}
RESUMO: As discussões acerca da avaliação escolar é algo que há muito tempo perpassa os estudos sobre trabalho docente no Brasil (LUCKESI, 2000; HOFFMANN, 2001). Essas discussões ganham novas cores com o processo de inclusão escolar, na qual começamos a tecer reflexões sobre práticas avaliativas com alunos com deficiência na escola regular (BRASIL, 2006; TEIXEIRA e NUNES, 2014). Assim, este artigo, fundamentando-se na perspectiva histórico-cultural de Vygotsky (1993[1945]), objetiva discutir como uma professora de língua inglesa compreende o processo de avaliação com um aluno com deficiência múltipla (DM). Os dados foram gerados em 2016, através de um questionário semiestruturado com uma professora de inglês do estado da Paraíba. A professora evidencia especificidades envolvidas nas práticas avaliativas com seu aluno com DM e, também, a necessidade de acreditarmos que o ensino de inglês para esses alunos é possível.
\end{abstract}

PALAVRAS-CHAVE: Ensino de língua inglesa. Deficiência múltipla. Avaliação.

ABTRACT: Discussions about school assessment have permeated studies on teaching activity in Brazil (LUCKESI, 2000; HOFFMANN, 2001). These discussions are being colored with new shades from inclusive education within debates about assessment practices to students with disabilities in mainstream schools (BRASIL, 2006; TEIXEIRA e NUNES, 2014). Therefore, considering Vygotsky's (1993[1945]) cultural historical theory of learning and development, this article aims at discussing the way an English teacher conceive the process of assessment to students with multiple disability. Data was generated in 2016 through a semi-structured questionnaire with an English teacher in the state of Paraíba, Brazil. The teacher demonstrates specificities involved in assessment practices to her student with multiple disability and also the need for us to believe that teaching English to these students is possible.

KEYWORDS: English teaching. Multiple disability. Assessment.

“ Doutoranda do Programa de Pós-graduação em Linguística da Universidade Federal da Paraíba. 
Introdução

E ousaram a aventura mais incrivel.

Viver a inteireza do possível

Andresen (1977)

As discussões sobre o ensino de línguas para pessoas com deficiência estão ganhando formas no mosaico da inclusão brasileira (MAGALHÃES, 2009; TONELLI, 2012; MEDRADO, 2014; OLIVEIRA, 2014). Tais estudos, com objetivos variados, unem-se na intenção de compreender as práticas pedagógicas envolvendo alunos com deficiência, revelando sua presença não apenas nos marcos legais, mas nas nossas escolas e salas regulares.

Nesse cenário, ressaltamos uma carência de reflexões teóricas e práticas sobre a avaliação escolar de alunos com deficiência, no âmbito do ensino de língua estrangeira (LE). Essa carência se faz ainda mais presente no contexto que investigamos - o ensino de língua inglesa para alunos com deficiência múltipla (DM) - e, por isso, consideramos importante ressaltar que esse contexto específico de trabalho é ainda mais complexo, haja vista que as associações e os níveis das deficiências apresentadas por cada indivíduo são diferentes, dificultando a disponibilização de modelos de agir (CLOT, 2010). Além disso, por se configurar como algo novo em nosso cenário educacional, recursos didáticos em LE, adaptados e específicos para alunos com deficiência, ainda são escassos, o que pode dificultar o desenvolvimento das atividades tanto para os professores, como para os alunos.

Dito isso, alinhando-nos à perspectiva histórico-cultural de Vygotsky (1993[1945]), aos pressupostos da avaliação escolar (LUCKESI, 2000; HOFFMANN, 2001) e às reflexões sobre o trabalho educacional com alunos com deficiência múltipla (LADEIRA; AMARAL, 1999; BRASIL, 2000; NUNES, 2001), objetivamos discutir como uma professora de língua inglesa compreende o processo de avaliação com um aluno com deficiência múltipla.

\section{0 aluno com deficiência múltipla na escola regular}


O direito ao acesso da pessoa com deficiência ao ensino regular, em todas as suas modalidades, é uma garantia legal, a qual pode ser verificada na Constituição Federal (BRASIL, 1988), que garante, nos artigos 205 e 206, o acesso de todos à educação e, na Lei 7.853/89 (BRASIL, 1989), em seu Art.8 , a pena de 1 a 4 anos e multa para instituições que negassem a matrícula de alunos por causa da deficiência. Esse Art. $8^{\circ}$ foi modificado pela Lei 13.146/15 (BRASIL, 2015a), constituindo crime de 2 a 5 anos a recusa da matrícula aos alunos com deficiência, reforçando, assim, a obrigatoriedade do acesso de todos à educação regular.

No âmbito dessa discussão, e pensado nos alunos com DM, ressaltamos a Resolução CNE/CEB 2/2001, que faculta a instituições de ensino

esgotadas as possibilidades pontuadas nos Artigos 24 e 26 da LDBEN, viabilizar ao aluno com grave deficiência mental ou múltipla, que não apresentar resultados de escolarização previstos no Inciso I do Artigo 32 da mesma Lei, terminalidade específica do ensino fundamental, por meio da certificação de conclusão de escolaridade, com histórico escolar que apresente, de forma descritiva, as competências desenvolvidas pelo educando, bem como o encaminhamento devido para a educação de jovens e adultos e para a educação profissional (BRASIL, 2001, p.04; grifo nosso).

A emissão dessa terminalidade específica não permite a continuidade dos estudos no Ensino Médio, uma vez que não houve conclusão da etapa do Ensino Fundamental (BRASIL, 2015b), o que parece inverter o eixo da legislação que garante o acesso de todas à educação, nos seus diversos níveis e modalidades. Desse modo, essa possibilidade deu continuidade a um modelo "que mantém alunos nas escolas e classes especiais, sem fluxo e progressão escolar, principalmente alunos com deficiência mental ou múltipla" (BRASIL, 2015b, p.149), revelando-nos não apenas contradições na legislação, mas também a dificuldade de encontrar, na escola regular, caminhos que ofereçam um ensino de qualidade, sendo, talvez, mais fácil colocar a responsabilidade na deficiência e, assim, eximir a escola, que ainda engatinha no processo inclusivo da educação desses alunos.

Nessa linha de pensamento, Vygostky (1993 [1934]) já defendia a educação de pessoas com deficiência também no espaço da escola regular para que pudessem interagir com diferentes outros, trocando conhecimento e, assim, ampliando suas experiências. Nesse sentido, o autor ressalta que a pessoa com deficiência, dependendo da deficiência, pode aprender por meios e caminhos 
diferentes dos habituais e que, por isso, os educadores necessitam conhecer as potencialidades e as limitações decorrentes da deficiência apresentada para que consigam encontrar esses caminhos até então não trilhados no espaço da escola regular.

Diante dessa reflexão, entendemos que conhecer as necessidades dos alunos, com ou sem deficiência, se faz imperativo para que o processo de ensinoaprendizagem seja orientado de maneira mais consciente. Assim, ao discutirmos sobre o ensino de inglês para alunos com deficiência múltipla, ressaltamos que esta é definida pela "associação de dois ou mais tipos de deficiência (intelectual/visual/auditiva/física)" (BRASIL, 2015b, p.46) e pode envolver as seguintes dimensões:

- Física e psíquica: deficiência física associada à deficiência mental; deficiência física associada a transtornos mentais;

- Sensorial e psíquica: deficiência auditiva associada à deficiência mental; deficiência visual associada à deficiência mental; deficiência auditiva associada a transtornos mentais;

- Sensorial e física: deficiência auditiva associada à deficiência física; deficiência visual associada à deficiência física;

- Física, psíquica e sensorial: deficiência física associada à deficiência visual e à deficiência mental; deficiência física associada à deficiência auditiva e à deficiência mental; deficiência física associada à deficiência auditiva e à deficiência visual (BRASIL, 2000a, p.54-55).

Por envolver diferentes dimensões, entendemos que as orientações para o trabalho docente com alunos com deficiência múltipla não podem ser generalizadas, uma vez que dependem da associação das deficiências e dos níveis em que se apresentam. A partir dessa compreensão, Nunes (2001) defende a necessidade de se conhecer a história clínica do indivíduo, principalmente no que diz respeito aos cuidados específicos indicados no diagnóstico, às implicações educacionais, aos efeitos dos medicamentos utilizados, às formas de comunicação específicas e às restrições físicas. Esses conhecimentos são de fundamental importância para o professor, uma vez que influenciam diretamente no processo de ensino- 
aprendizagem como, por exemplo, quando o aluno toma uma medicação que causa sonolência, diminuindo sua concentração/participação na sala de aula.

Nessa linha de pensamento, Orelove e Sobsey (2000 apud NUNES, 2001) ressaltam que o indivíduo com DM pode apresentar um conjunto de necessidades diversas, que, segundo os autores, podem ser agrupadas em:

- Necessidades físicas e médicas: adequação de atividades tendo em vista que os movimentos voluntários são limitados em termos qualitativos e quantitativos e podem apresentar limitações sensoriais (sobretudo as visuais e as auditivas), convulsões e dificuldades no controlo respiratório e pulmonar devido aos problemas musculares e esqueléticos;

- Necessidades emocionais: como todos os alunos, necessitam de afeto e atenção, com oportunidades para interagir no contexto em que estão inseridos e com os adultos e/ou seus pares;

- Necessidades educativas: adaptações de atividades devido às limitações na fala e, consequentemente, na comunicação. Adaptações do ambiente físico escolar e dos materiais didáticos e metodologias por causa das restrições motoras e sensoriais.

As necessidades, portanto, pressupõem adequações/adaptações que não podem ser ignoradas diante do objetivo educacional de criar um espaço acessível de aprendizagem. Assim, pensando nessas necessidades e adequações/adaptações, ressaltamos, como base em Ladeira e Amaral (1999), Brasil (2000b, 2015) e Nunes (2001), algumas ações que se fazem premente na inclusão de pessoas com DM:

- Formação inicial e continuada para os docentes;

- Adaptações curriculares de conteúdos, metodologias e avaliações;

- Reorganização da sala de aula, para que o aluno possa sentar no local mais adequado em termos de acessibilidade, interação e luminosidade;

- Disponibilização de objetos, letras e imagens com tamanhos, cores e contrastes que facilitem a compreensão;

- Disponibilização de mais tempo para que o aluno possa tomar iniciativas e para que responda ao que foi solicitado;

- Criação de rotinas de apoio para que os colegas auxiliem nas atividades; 
- Incentivo ao envolvimento da família, dos alunos e dos demais membros da escola no processo de aprendizagem;

- Disponibilização de materiais em braille, em libras e recursos, como lupas, lápis e cadernos adaptados, pranchas de apoio para leitura, dentre outros.

- Presença de intérprete de libras, monitor e cuidador;

- Auxílio dos profissionais do Atendimento Educacional Especializado (Sala de Recursos);

- Incentivo a autonomia do aluno, com participação total ou parcial nas atividades, com e sem auxílio;

- Conscientização, a fim de eliminar preconceitos e outras barreiras atitudinais na construção de um espaço em que todos possam contribuir para a aprendizagem uns dos outros.

Essas ações, reforçamos, não envolvem apenas o professor da sala de aula regular, mas todos os membros que fazem parte da educação, em um processo, como nos lembram Maia e Ikonomidis (2013), de responsabilidade partilhada, já que incluir é um projeto coletivo, em que cada um fazendo a sua parte, movimenta a inclusão de todos.

\section{Avaliação na inclusão escolar}

De acordo com Luckesi (2000) e Teixeira e Nunes (2014), as práticas avaliativas no Brasil, em sua maioria, são utilizadas apenas para classificar os alunos em aprovados e reprovados; isto é, o objetivo de identificação e remoção das barreiras (BRASIL, 2006) é pouco atingido. Com isso, os autores defendem que essas práticas sejam repensadas para que a avaliação possa, de fato, ser entendida como uma prática de investigação (TEIXEIRA e NUNES, 2014), possibilitando o conhecimento e a compreensão das potencialidades e dos limites de cada aluno, para que se tenha mais subsídios para o desenvolvimento do objeto de aprendizagem: a língua inglesa, nesta pesquisa.

Pensando no ensino para alunos com deficiência na escola regular, as práticas avaliativas ganham novas formas, pois, dependendo do comprometimento advindo da deficiência, adaptações/adequações, até então não presentes no sistema educacional regular, são apresentadas como essenciais. Nesse sentido, o 
Ministério da Educação (MEC) lança as Adaptações curriculares de pequeno porte e de grande porte, destinadas ao ensino de pessoas com deficiência, pontuando adaptações curriculares em termos de objetivos, métodos de ensino, organização didática, processo de avaliação e temporalidade do processo de ensino e aprendizagem (BRASIL, 2000b).

Além dessas adaptações, o MEC lança o documento Saberes e práticas da inclusão - avaliação para identificação das necessidades educacionais especiais (BRASIL, 2006), fornecendo uma gama de informações sobre os processos avaliativos no âmbito da inclusão. Ele ressalta que o processo de avaliação depende de três dimensões: o contexto escolar, os alunos e a família.

O contexto escolar abrange a instituição educacional escolar (crenças, valores, questões estruturais e funcionais) e a ação pedagógica (o professor, a sala de aula, os recursos de ensino e de aprendizagem, as estratégias metodológicas usadas para o ensino dos conteúdos curriculares e estratégias avaliativas); a dimensão dos alunos envolve o nível de desenvolvimento (características funcionais e competências curriculares) e as condições pessoais (a natureza das necessidades educacionais que apresenta), e a dimensão da família é apresentada pelo MEC em termos de características do ambiente familiar (condições físicas da moradia, cultura, valores em que acredita e atitudes frente à vida e expectativas de futuro) e convívio familiar (pessoas que convivem com o aluno, relações afetivas, qualidade das comunicações e oportunidades de desenvolvimento e de conquista da autonomia). Percebemos, a partir desses níveis, que o sucesso ou o fracasso do aluno não depende exclusivamente dele, mas de todas as interações envolvidas na trama inclusiva.

Ancorada nesse entendimento, tal política educacional chama a atenção para a responsabilidade do professor nas práticas de avaliação, alertando para "um agir consciente e reflexivo frente às situações avaliadas" (BRASIL, 2006, p.81-82). Isto é, após compreender um pouco as condições dos alunos, em termos de necessidades físicas, cognitivas e emocionais, os professores necessitam fazer escolhas, as quais afetam todo o processo de ensino-aprendizagem, devendo, por isso, ser éticas e conscientes.

Nessa linha de pensamento, Luckesi (2000) afirma que a avaliação envolve dois processos indissociáveis: diagnosticar e decidir. Para o autor, a avaliação só se completa quando o professor toma a decisão diante do que foi verificado, indicando 
caminhos mais adequados para o desenvolvimento do aluno. Além disso, ele discute que, para qualificar os resultados obtidos no diagnóstico, é necessário "por um lado, ter clara a teoria que utilizamos como suporte de nossa prática pedagógica, e, de outro, o planejamento de ensino que estabelecemos" (p. 06), pois os dados serão qualificados diferentemente, dependendo da teoria e do planejamento adotados. Isto é, a maneira como compreendemos as práticas educacionais e, por conseguinte, as avaliativas é um aspecto basilar do processo inclusivo.

Ademais, Luckesi (2000) ressalta que avaliar um educando envolve uma disposição para acolher, pois "implica, antes de mais nada, acolhê-lo no seu modo de ser" (p.01), não sendo possível avaliar, caso a pessoa "seja recusada ou excluída, desde o início, ou mesmo julgada previamente" (p. 01). Avaliar, portanto, evolve afetividade, equidade e um posicionamento ético de inclusão. Essa disposição para o acolhimento, segundo Luckesi (2000), não é algo nato, mas construído e, por isso, precisamos estar atentos ao modo como afetamos e nos deixamos ser afetados (SPINOZA, 2014 [1677]) pelos outros, pelas atividades, ações, discursos e artefatos que fazem parte do nosso trabalho docente.

Nessa perspectiva, faz-se necessário compreender que avaliação não é sinônimo de exames (LUCKESI, 2000), ou pelo menos não deveria ser, mas se configura como práticas educativas inerentes ao processo de aprendizagem, as quais auxiliam professores e alunos e, por isso, não podem ser negadas a nenhum estudante. Seguindo essa linha de pensamento, Teixeira e Nunes (2014) destacam que as práticas avaliativas se fazem necessárias, pois são atos inclusivos em que se avalia "para conhecer e se conhece para avaliar" (p. 50). É uma dialética em que precisamos avaliar para conhecer as potencialidades e dificuldades dos alunos e, assim, traçar um planejamento a ser atingido no processo contínuo de avaliação. Nesse sentido, a avaliação se apresenta como uma ferramenta para o desenvolvimento da inclusão escolar.

No âmbito dessas práticas avaliativas, que são direito de todos, e ao compreendermos que cada aluno experimenta o mundo de maneira diferenciada, ressaltamos, ainda, que o padrão a ser alcançado no processo de aprendizagem não deve ser o mesmo para todos os alunos, ou como defende Teixeira e Nunes (2014, p.76), é necessário respeitar o aluno "comparando ele com ele mesmo", sendo o sucesso um padrão individual e não coletivo. 


\section{Metodologia}

A fim de alcançarmos os objetivos da pesquisa, optamos por uma metodologia de cunho qualitativo-interpretativista, por trabalhar com o conhecimento e a subjetividade dos envolvidos (FLICK, 2004) que, em nosso caso, é uma professora de língua inglesa.

Nossos dados foram gerados por meio de um questionário semiestruturado e as perguntas versaram, principalmente, sobre o processo de avaliação da língua inglesa com o aluno com deficiência múltipla, a partir de 2015 (período em que nossa colaboradora começou a trabalhar com esse aluno). O questionário foi enviado por email no dia 13 de junho de 2016, e a professora respondeu a ele em 18 de junho do mesmo ano.

Nossa colaboradora, professora de língua inglesa de um Instituto Federal (IF), com experiência docente de 16 anos, é denominada ficticiamente como Marina. Desde 2015, Marina começou a lecionar para um aluno com deficiência múltipla, nomeado de Marcelo. Ele, que está com 21 anos de idade e matriculado no $3^{\circ}$ ano do curso médio-técnico de Informática, é cadeirante, apresenta dificuldades para falar e respirar, tem deficiência visual (baixa visão) e atrofia muscular com limitações motoras para mover os braços e segurar objetos.

Com relação ao contexto das aulas de língua inglesa, em 2015, Marina lecionava para Marcelo em um horário extra (para repor as aulas que ele perdeu em 2014, devido à sessões de fisioterapia), fora da carga horária de ambos, com aulas individuas. Já neste ano de 2016, apesar de o curso médio-técnico que Marcelo faz não oferecer inglês no $3^{\circ}$ ano, eles continuaram com as aulas individuais. Por meio de um projeto de ensino de línguas desenvolvido por Marina dentro do IF, Marcelo também estuda em uma turma regular com mais 25 alunos, somando um total de 3h30min de aulas por semana.

O campus do Instituto Federal, contexto da nossa pesquisa, por meio do Núcleo de Apoio a Pessoas com Necessidades Especiais (NAPNE), oferece assistência específica a alunos com deficiência, com o apoio de pedagogos, cuidadores, intérpretes de libras, transcritores e materiais acessíveis em braille.

\section{As múltiplas possibilidades exploradas}


Iniciamos nosso diálogo com as reflexões de Marina sobre o seu trabalho com Marcelo, quando ela nos fala que:

\author{
Excerto 01 \\ No início, como na maioria dos inícios, foi meio complicado. \\ Entretanto, ao longo das aulas conseguimos nos entender. Eu \\ sentava com ele no final da aula e perguntava o que havia achado e \\ o que gostaria que tivesse na aula seguinte.
}

Marina nunca havia trabalhado com alunos com deficiência múltipla antes; ela estava diante de um novo cenário educacional, para o qual muitas das ferramentas disponíveis (AMIGUES, 2004) que ela conhecia para o ensino de inglês pareciam não servir e, por isso, ela nos revela que foi algo meio complicado. No entanto, ela encontra em Marcelo uma possibilidade de acesso a ferramentas que facilitem seu trabalho nesse novo contexto e ela explora essa possibilidade, sentando todo final de aula com ele e perguntando o que havia achado e o que sugeria. Marcelo, portanto, não era apenas o novo desafio no trabalho da professora, mas também aquele que iria ajudá-la na superação desse desafio, construindo juntos espaços de aprendizagem para além do currículo escolar. Vejamos:

\title{
Excerto 02
}

Não é pela ausência da disciplina na grade curricular que temos nossas aulas. É por questão de necessidade e vontade dele e minha. Excerto 03

Eu sempre desejei trabalhar com avaliação não quantitativa. Tenho problemas com números, porque eu não concebo quantificar o conhecimento. Acredito que esse tipo de avaliação que faço com o Marcelo é possível, porque trabalhamos 1 para 1. Eu não tenho outros alunos na turma. É só ele. A atenção é só para ele.

Marina destaca que o fato de ministrar aulas individuais para Marcelo facilita um trabalho com práticas avaliativas mais qualitativas, uma vez que consegue dar mais atenção ao aluno, algo menos viável quando está na sala com a turma toda. Essa fala de Marina lembra o pensamento de Vygostky (1993 [1934]) de que não podemos negar as necessidades dos alunos; no caso de Marcelo, a professora percebe que ele necessita de uma atenção maior para que possa se desenvolver mais na língua estrangeira e explora, nas aulas individuais, essa possibilidade de desenvolvimento. Essas aulas individuais, portanto, também fazem parte da inclusão 
de Marcelo, pois incluir não pode ser apenas coletivo de pessoas, mas de oportunidades.

Além disso, como pontuamos na metodologia, Marcelo tem 3h30min de aulas de inglês semanais, que não fazem parte do currículo escolar, e isso acontece por necessidade e vontade dele e da professora. Essa reflexão de Marina nos conduz, em um primeiro momento, ao pensamento de Friedrich (2012, p.116) ao dizer que os estudantes necessitam se envolverem na construção da aula, pois "[...] sem a resposta do aluno, sem sua participação ativa, as aprendizagens são condenadas ao fracasso". O aluno é, desse modo, um dos responsáveis pelo desenvolvimento da aula, independentemente da sua deficiência. Essa responsabilidade Marcelo parece cumprir.

Por outro lado, essa discussão nos mostra, igualmente, a tomada de responsabilidade de Marina, que disponibiliza um tempo extra para ministrar aulas individuais. É um posicionamento ético-profissional para oportunizar a Marcelo acesso ao processo de ensino-aprendizagem da língua inglesa, que, de outro modo, não estava sendo possível. Marina nos mostra, portanto, que disponibilizar um tempo extra para que a inclusão de alunos com deficiência possa ser efetivada não é algo surreal no trabalho docente.

Além de ressaltar as aulas individuais, Marina reflete sobre o desenvolvimento de Marcelo no coletivo da turma do projeto de inglês:

\section{Excerto 04}

A atividade era um texto para ser representado como uma peça de teatro. Todos os alunos fizeram uma espécie de coreografia, mexendo os braços. O que para nós é tão simples - mexer os braços - para ele, é praticamente impossível, ainda mais com velocidade. $\mathrm{E}$ ele ficava olhando... O que será que estava pensando? A minha grande sorte é que todos aceitaram muito bem a presença dele, e um aluno, em especial, Rafael, deu todo o suporte para ele. Eu quero muito que o Marcelo se sinta inserido na turma, que os alunos estejam ao redor dele, que compartilhem conversas com ele.

Essa discussão nos remete ao pensamento de Luckesi (2000), ao dizer que avaliar pressupõe incluir o aluno do jeito que ele é; pressupõe acolhimento. Refletindo sobre as aulas no âmbito do projeto de inglês, Marina demonstra a preocupação de que Marcelo se sinta incluído com os demais alunos, aceitando sua presença e colaborando para o seu desenvolvimento; ou seja, existe uma 
necessidade de acolhimento não só por parte da professora, mas de toda a turma, pois Marcelo, assim como qualquer outro aluno, precisa ter uma relação harmônica com seus colegas para que o ambiente de aprendizagem seja um coletivo em que todos aprendam juntos.

Associado a esse acolhimento, chama-nos a atenção o suporte que os colegas deram para Marcelo, pois, como já mencionado pela professora, ele precisa de mais atenção, tendo em vista as dificuldades motoras e sensoriais. $E$ os outros alunos são fundamentais nesse auxílio, como destacado por Nunes (2001), que ressalta o papel dos colegas no processo de aprendizagem do aluno com DM. Os resultados das práticas avaliativas de cada um envolvem, portanto, o acolhimento e o suporte de todos. Nesse cenário, Marina também discute a importância da família e do cuidador. Vejamos nos excertos a seguir:

\begin{abstract}
Excerto 05
Converso muito com a mãe dele. Ela é extremamente dedicada, preocupada e, principalmente, consciente de todo o processo de desenvolvimento da aprendizagem do Marcelo. Ela dá apoio $100 \%$.

Excerto 06

A mudança de lugar da cadeira de rodas dele também foi realizada para que ele enxergasse melhor, para que o reflexo da luz não o atrapalhasse. Interessante que após essa mudança, o aprendizado passou a ser mais rápido. Ele demorava muito mais tempo para ler o que estava no quadro. Foi o cuidador dele que suscitou essa situação.
\end{abstract}

A mãe de Marcelo dá apoio 100\%; é dedicada, preocupada e consciente do aprendizado do aluno. Ao trazer essa reflexão no excerto 05, Marina demonstra o papel da família no desenvolvimento do aluno, corroborando a discussão feita pelo MEC (BRASIL, 2006), em uma de suas políticas sobre avaliação inclusiva, de que uma das dimensões da avaliação é a família - as características do ambiente e o convívio familiar. Esse apoio da família de Marcelo se apresenta como fundamental em todo o processo aprendizagem, pois a participação dele nas aulas de inglês (individuais e em grupo) ocorre nos contraturnos das aulas regulares do curso. Assim, os pais precisam se deslocar para levá-lo ao IF mais duas vezes por semana para essas atividades extras, que não fazem parte do currículo escolar. Nesse sentido, a família, também explorando as possibilidades de aprendizagem para Marcelo, atua como um instrumento para o seu desenvolvimento. 
Outra dimensão da avaliação, de acordo com essa mesma política do MEC, é o contexto escolar - a instituição educacional escolar e a ação pedagógica - no âmbito da qual encontramos o cuidador, que auxilia os alunos com deficiência "em razão de limitações para a prática de atividades da vida diária, tais como locomoção, higienização, alimentação ou comunicação" (BRASIL, 2014, p. 02). O cuidador acompanha o aluno com deficiência em todas as dependências da escola e, por isso, é parte integrante da aprendizagem e do desenvolvimento do aluno, como ressaltou Marina no excerto 04, ao pontuar a mudança de lugar de Marcelo na sala de aula para enxergar melhor o que estava sendo exposto no quadro.

Nesse sentido, o apoio dos colegas, da família e do Atendimento Educacional Especializado, por meio do cuidador, evidencia que o processo avaliativo não é construído apenas na relação aluno-professor, mas no coletivo das relações vivenciadas por cada um, que ultrapassam os muros escolares. Além desse caráter coletivo do aprendizado e, por conseguinte, das práticas avaliativas, Marina nos chama a atenção para as adaptações necessárias no trabalho com Marcelo:

\begin{abstract}
Excerto 07
Como ele tem problemas de visão, o material impresso é todo adaptado para ele. A letra é tamanho 18 e na maioria das vezes quando ele tem que ler, eu seguro a folha em uma altura acima dos olhos. Devido à atrofia muscular que possui e a dificuldade para escrever, não exijo que ele faça handwriting. [...] a parte escrita é mais trabalhada em casa porque ele faz tudo no computador. [...] Esse ano, optei por fazer tudo no Power Point. Corrijo no próprio Power Point e discutimos a correção [...] O problema de respiração também faz com que eu tenha um cuidado maior com ritmo e velocidade da fala.
\end{abstract}

A partir desse excerto, retomamos o pensamento de Vygotsky (1993[1945]), ao afirmar que o aluno com deficiência aprende por meios e caminhos diferentes dos habituais, sendo necessário adaptações/adequações que permitam o acesso a esses meios e caminhos. Marina nos revela, dentro das suas possibilidades, algumas das adaptações/adequações realizadas com seu aluno com DM, tais como: ampliação da fonte, posição do texto, escrita e correção no computador, ritmo e velocidade da produção oral. Esses processos, compreendemos, se configuram como atitudes necessárias para que o aluno tenha acesso ao conhecimento, desenvolvendo suas potencialidades, e para que possa avaliar-se e ser avaliado de maneira mais consciente. 
Além dessas adaptações/adequações, Marina ressalta a importância da dimensão psicológica no trabalho com Marcelo. Vejamos:

\begin{abstract}
Excerto 08
Eu tenho que estar sempre atenta à dimensão psicológica dele. É um dos fatores, talvez o maior, que influencia o aprendizado dele e o meu trabalho. Há dias em que o olhar perdido dele, seja por uso dos remédios, doença ou situações familiares, demanda de mim muito mais atenção.
\end{abstract}

Na sua fala, Marina nos chama a atenção para as necessidades médicas e emocionais do aluno com DM, como destacado por Orelove e Sobsey (2000 apud NUNES, 2001) em nossas reflexões teóricas. As necessidades médicas de Marcelo, tais como o uso de medicamentos, interferem no seu envolvimento na aula, solicitando mais atenção por parte de Marina, assim como as necessidades emocionais decorrentes de situações familiares, que intervêm tanto no aprendizado de Marcelo, como no trabalho da professora. Essas necessidades, segundo Marina, se configuram em um dos fatores, talvez o maior, que mais influencia no processo de ensino-aprendizagem e, por isso, não podem ser desconsideradas quando pensamos na avaliação como uma prática inclusiva.

Dada sua importância para o trabalho docente, faz-se premente conhecer as necessidades dos alunos com DM (médicas, físicas, emocionais e educacionais) que recebemos em nossas salas de aula para que, assim, possamos desenvolver uma prática educativa mais condizente com a realidade apresentada. Além desse conhecimento necessário para avaliação, quando entendida como prática educativa (PARAÍBA, 2010), chamamos a atenção para os seguintes trechos da fala de Marina:

\title{
Excerto 09
}

Eu sou adepta de um processo avaliativo diário. Eu prefiro avaliá-lo ao longo das nossas aulas. Como ele tem exercícios para casa, seja estudar uma música e procurar pelas palavras novas ou responder algumas questões ou ainda desenvolver diálogos, eu considero tudo isso a avaliação dele. Gosto mais de conversar sobre o desenvolvimento dele do que dar uma nota que nem sempre reflete o que ele está aprendendo.

\section{Excerto 10}

Em reuniões de conselho de classe, ele era sempre o assunto que demandava mais discussões. Muitos professores achavam que ele deveria ficar reprovado, porque não tinha atingido o mínimo exigido. 
Será que a aprovação e a reprovação são mais importantes do que a socialização desse aluno? E que mínimo exigido é esse? Mínimo quantitativo!

Nos excertos 09 e 10, Marina deixa transparecer seu posicionamento teórico acerca das práticas pedagógicas e, por conseguinte, das práticas avaliativas com Marcelo, ressaltando que é adepta de uma avaliação contínua, a qual não prioriza a nota como instrumento para atingir um mínimo quantitativo. Nesse processo, ela nos permite entender que mais importante do que a aprovação e a reprovação é a socialização do aluno com deficiência múltipla, sua convivência com os colegas.

Esse posicionamento teórico da professora, segundo Luckesi (2000), é fundamental para o processo avaliativo, pois é ele que direciona como as produções do aluno serão avaliadas. Assim, por exemplo, estudar uma música e procurar pelas palavras novas ou responder a algumas questões ou ainda desenvolver diálogos é considerado, por Marina, como avaliação da aprendizagem de Marcelo. Nesse sentido, é necessário ficarmos atentos ao modo como compreendemos as práticas educativas, pois nossa compreensão pode se configurar como base de desenvolvimento ou de impedimento no processo avaliativo de nossos alunos.

A partir desse panorama, percebemos não apenas que as práticas avaliativas desenvolvidas com Marcelo são múltiplas, mas que são sempre uma construção coletiva diante das possibilidades encontradas. Ou seja, Marina não está realizando algo impossível no seu trabalho docente, mas explorando possibilidades que muitas vezes não são ou não querem ser percebidas.

\section{Considerações finais}

A fala de Marina revela, por um lado, nuances envolvidas no processo avaliativo com seu aluno com deficiência múltipla, tais como a necessidade de aulas individuais, o envolvimento da família e do cuidador, as adaptações/adequações necessárias, a importância do conhecimento acerca das necessidades físicas, médicas, emocionais e educacionais do aluno, assim como o posicionamento teórico acerca das práticas educativas. Essas especificidades evidenciam uma discussão acerca de um contexto escolar com desafios muito pouco abordados nas pesquisas sobre ensino de línguas, contribuindo com novos saberes docentes para a avaliação 
de pessoas com DM e alertando para uma formação docente que discuta as práticas avaliativas em contextos com alunos com deficiência.

Por outro lado, as reflexões de Marina também deixam transparecer que o trabalho com Marcelo só se concretizou porque ela acreditou não apenas que ele era capaz de aprender a língua inglesa, mas também que ela seria capaz de ensinar e aprender com um aluno com deficiência múltipla. Parafraseando o que poetizou Andresen (1977) na epígrafe deste artigo, Marina, dentre os inúmeros desafios e limitações, ousou viver a aventura mais incrível do trabalho inclusivo: explorar a inteireza do possível.

\section{Referências}

AMIGUES, R. Trabalho do professor e trabalho de ensino. In: MACHADO, Anna Rachel (Org.) O ensino como trabalho. São Paulo: EDUEL, 2004.

ANDRESEN, S. M. B. Navegações - As ilhas. [1977]. Disponível em: < http://escritafone.blogspot.com.br/2014/02/sophia-de-mello-breyner-andresen-contos.html>. Acesso em: 06 Jul 2016.

BRASIL. Constituição 1988. Constituição da República Federativa do Brasil: promulgada em: 5 de outubro de 1988. Art. 205 e 206. Disponível em: <http://www. planalto.gov.br/ccivil_03/constituicao/constituicaocompilado.htm>. Acesso em: 20 Jun. 2016.

. Lei $n^{\circ} 7.853$, de 24 de outubro de 1989. Dispõe sobre o apoio às pessoas portadoras de deficiência, sua integração social. Disponível em: <http://www.planalto.gov.br/ccivil_03/leis/l7853.htm>. Acesso em: 20 Jun. 2016.

- Programa de capacitação de recursos humanos do ensino fundamental:

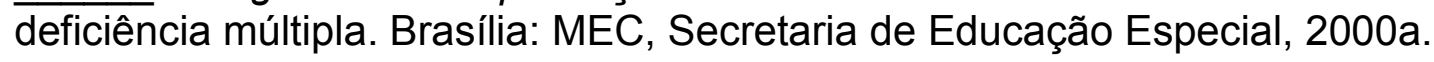

- Projeto Escola Viva - Garantindo o acesso e permanência de todos os alunos na escola - Alunos com necessidades educacionais especiais - Adaptações de pequeno porte. Brasília: MEC, Secretaria de Educação Especial, 2000b.

. Resolução CNE/CEB $n^{\circ}$ 2, de 11 de setembro de 2001. Institui Diretrizes Nacionais para a Educação Especial na Educação Básica. Disponível em: <http://portal.mec.gov.br/cne/arquivos/pdf/CEB0201.pdf>. Acesso em: 01 Jul. 2016.

Saberes e práticas da inclusão: avaliação para a identificação das necessidades educacionais especiais. Brasília: MEC, Secretaria de Educação Especial, 2006. 
Projeto de lei do senado $n^{\circ} 228$, de 2014. Altera a Lei $n^{\circ} 9.394$, de 20 de dezembro de 1996, que estabelece as diretrizes e bases da educação nacional, para, quando necessário, assegurar ao educando com deficiência a assistência de cuidador nas escolas. Disponível em: <http://www.senado.leg.br/atividade/rotinas/ materia/getPDF.asp?t=153268\&tp=1>. Acesso em: 21 Jun 2016.

Lei $n^{\circ}$ 13.146, de 6 de julho de 2015. Estabelece a Lei Brasileira de Inclusão. (2015a) Disponível em: <http://www.planalto.gov.br/ccivil_03/_Ato20152018/2015/Lei/L13146.htm>. Acesso em: 21 Mai 2016.

. Orientações para implementação da política de educação especial na perspectiva da educação inclusiva. Brasília: MEC, Secretaria de Educação Especial, 2015b.

CLOT, Y. Trabalho e Poder de Agir. Belo Horizonte: Fabrefactum, 2010.

FLICK, Uwe. Uma introdução à pesquisa qualitativa. Porto Alegre: Bookman, 2004.

FRIEDRICH, J. Lev Vigotski: mediação, aprendizagem e desenvolvimento: uma leitura filosófica e epistemológica. São Paulo: Mercado de Letras, 2012.

HOFFMANN, J. Avaliar para promover: as setas do caminho. Porto Alegre: Mediação, 2001.

LADEIRA, F.; AMARAL, I. Alunos com multideficiência nas escolas de ensino regular. Lisboa: Ministério da Educação, 1999.

LUCKESI, C. C. O que é mesmo o ato de avaliar a aprendizagem? Pátio. Rio Grande doSul, n.12, p. 6-11, fev/mar. 2000.

MAIA, S. R. IKONOMIDIS, V. M. Deficiência múltipla sensorial. In.: SALA, E. ACIEM, T. M. (Orgs.). Educação inclusiva: aspectos político-sociais e práticos. Jundiaí: Paco editorial, 2013.

MAGALHÃES, G. M. A cultura de aprender E/LE do aluno cego: um olhar para a inclusão. 2009. 201f. (dissertação) - Universidade de Brasília, Brasília, 2009.

MEDRADO, B. P. (Org.). Deficiência visual e ensino de línguas estrangeiras: políticas, formação e ações inclusivas. Campinas, SP: Pontes, 2014.

NUNES, C. Aprendizagem Activa na Criança com Multideficiência: guia para educadores. Lisboa: Ministério da Educação, 2001.

OLIVEIRA, A. A. A prática docente de língua inglesa para estudantes surdos e ouvintes usando o livro didático e o computador: um estudo de caso sob a ótica da teoria da atividade. 2014. 221f. (dissertação) - Universidade Federal de Lavras, Lavras, 2010.

PARAÍBA. Referenciais Curriculares do Ensino Fundamental da Paraíba. João Pessoa: SEEC, 2010. 
$\mathbb{B}_{\text {ปisgei }} \mathcal{A}$

SPINOZA, B. Ética. Belo Horizonte: Autêntica, 2014 [1677].

TEIXEIRA, J. NUNES, L. Avaliação inclusiva: a diversidade reconhecida e valorizada. Rio de Janeiro: Wak Editora, 2014.

TONELLI, J. R. A. A "dislexia" e o ensino-aprendizagem da língua inglesa. 2012. 574f. (Tese) - Universidade Estadual de Londrina, Londrina, 2012.

VYGOTSKY, L. S. The Fundamentals of Defectology (Abnormal Psychology and Learning Disabilities) In: The Collected Works of L. S. Vygotsky. New York: Plenum Press, 1993 [1934]. 